\title{
Screening for suppressors of temperature sensitivity in a yeast mutant defective in vacuolar protein degradation
}

\author{
Martin Götte $e^{1,2}$ \\ ${ }^{1}$ Protogenia Research Laboratory, Protogeneia, Inc., Münster, Germany. \\ ${ }^{2}$ Max-Planck-Institute for Biophysical Chemistry, D-37018 Göttingen, Germany.
}

\begin{abstract}
Vps33p is a member of the Sec1/munc18-like protein (SM protein) family involved in vesicular protein transport to the yeast vacuole. It is part of a high molecular weight complex which is required for homotypic vacuole fusion, and participates in Golgi-to-endosome and endosome-to-vacuole transport steps. Deletions in the vps33 gene result in severe vacuolar protein sorting and vacuolar morphology defects. We used a temperature sensitive (ts) vps33 deletion strain in a high copy plasmid suppressor approach to identify genes possibly acting along the same vesicular trafficking pathway(s) as Vps33p. While only the original VPS33 gene could restore the vacuolar enzyme sorting and vacuolar morphology defects, several suppressors of temperature sensitivity were found. Sequence analysis identified the ubiquitin-ligase Ufd4p as the only open reading frame (ORF) of two suppressor plasmids. Further suppressor candidates included the ubiquitin-processing protease Ubp10p and genes whose products are involved in more general stress responses. The result of this screening supports the emerging concept of a crosstalk between vesicular trafficking pathways and the ubiquitin/proteasome system of protein degradation.
\end{abstract}

Key words: VPS33, UFD4, lysosomal trafficking, ubiquitin, endosome.

Received: June 6, 2002; accepte: December 4, 2002.

\section{Introduction}

The vacuole of baker's yeast Saccharomyces cerevisiae is the functional equivalent of the lysosome of higher eukaryotic cells. Apart from playing roles in the storage of metabolites and in regulation of ion homeostasis, its main function is the degradation of macromolecules (Klionsky et al., 1990). The vacuole harbors a variety of hydrolases, which, after biosynthesis in an inactive precursor form, enter the lumen of the endoplasmic reticulum (ER) and are transported in vesicles to the Golgi apparatus. In a late Golgi-compartment, they are separated from secretory proteins in an active sorting process and finally reach the vacuole trafficking through endosomal / prevacuolar compartments (Götte and Lazar, 1999). Proteolytic activation of the proenzymes takes place in the acidic environment of the vacuolar lumen (van den Hazel et al., 1996).

Mutations in over 50 genes lead to maturation and secretion defects of vacuolar enzymes and to changes in vacuolar morphology and function. Among these, the VPS (vacuolar protein sorting) mutants, which were isolated based on the secretion of vacuolar hydrolases, constitute

Send correspondence to M. Götte. Protogenia Research Laboratory, Protogeneia, Inc., Mendelstr. 11, D-48149 Münster, Germany. E-mail: protogenia@technologiehof-ms.de. the largest group (Robinson et al., 1988; Rothman et al., 1989). Mutations in the VPS genes partially overlap with mutants displaying a vacuolar aberrant morphology (VAM) (Wada et al., 1992). Based on biochemical and morphological criteria, the vps mutants were grouped into 5 classes, named A-E (Raymond et al., 1992). The four class C mutants, which are identical to the class I vam mutants, display the most severe vacuolar protein-sorting and vacuolar morphology defects. A highly fragmented, barely visible vacuole, and maturation and/or sorting defects of the vacuolar enzymes carboxypeptidase Y (CPY), proteinase A (PrA), proteinase $\mathrm{B}(\operatorname{PrB})$, and alkaline phosphatase (ALP) are characteristic for these mutants. A complex consisting of the class C Vps proteins, as well as Vam6p and Vam4p, stimulates nucleotide exchange on the Ypt7p GTPase, and is required for homotypic vacuole fusion (Seals et al., 2000; Wurmser et al., 2000). It has been proposed that the class $\mathrm{C}$ Vps complex associates with the activated syntaxin-related Vam3-protein to mediate the assembly of trans-SNARE complexes during both vesicle docking/fusion and vacuole-to-vacuole fusion (Sato et al., 2000). Genetic and biochemical data suggest that the class $\mathrm{C}$ Vps complex is required for membrane docking and fusion at both the Golgi-to-endosome and endosome-tovacuole transport steps (Peterson and Emr, 2001). 
Recently, the involvement of ubiquitin in targeting of proteins to the endocytic and vacuolar protein-sorting pathways has become the focus of intense research (Amerik et al., 2000; Reggiori and Pelham, 2001; Katzmann et al., 2001). The 76aa-residue protein ubiquitin is covalently conjugated to proteins marked for ATP-dependent degradation by the $26 \mathrm{~S}$ proteasome, a multi-subunit protease complex (Voges et al., 1999). Ubiquitin-activating and ubiquitin-conjugating enzymes, as well as ubiquitin-ligases, are involved in this process. The regulated protein degradation by this ubiquitin-proteasome system plays a role in processes as diverse as stress responses, the cell cycle, and differentiation (Hershko and Ciechanover, 1998; Glickman and Ciechanover, 2000). Ubiquitin-ligases are found at multiple sites along the endocytic pathway in yeast (Wang et al., 2001; Shin et al., 2001), and ubiquitin has been shown to target certain transmembrane proteins to invaginating endosomal vesicles and multivesicular bodies (Reggiori and Pelham, 2001, 2002).

We used a multicopy plasmid suppressor screening, a proven tool in studying vesicular trafficking mutants (Dascher et al., 1991; Götte and Gallwitz, 1997), to identify new genes possibly involved in a similar vesicular trafficking step as the class $C$ vps protein Vps33p (Banta et al., 1990; Wada et al., 1990). The Vps33p ATPase belongs to the group of Sec1/Munc18-related SM proteins and is part of the class C Vps complex involved in homotypic vacuole fusion (Seals et al., 2000; Wurmser et al., 2000; Sato et al., 2000). vps 33 mutants are characterized by maturation defects of the vacuolar proteins CPY, PrA and vgp72, by the lack of a visible vacuole, and by a growth defect on lysinerich media (Wada et al., 1990), as well as by defects in methionine metabolism (Jaquemin-Faure et al., 1994). Apart from candidate genes known to be involved in general stress responses, we identified a gene of the ubiquitin pathway and a second candidate gene acting along the same pathway as suppressors of temperature sensitivity of $v p s 33$. The results of this screening provide further support to the emerging concept of a crosstalk of the ubiquitin and endocytic pathways.

\section{Materials and Methods}

\section{Materials}

Except stated otherwise, all reagents were from Sigma, Deisenhofen, Germany. Restriction endonucleases and other enzymes for DNA manipulation were from New England Biolabs, Schwalbach, Germany. Zymolyase 100-T was from Seikagaku, Kogyo, Tokyo, Japan. $\operatorname{Tran}^{35} \mathrm{~S}$-label was from Amersham-Buchler, Meckenheim, Germany. The vector pBluescript II KS + was from Stratagene, Heidelberg, Germany.

\section{Strains, growth of cells and construction of plasmids}

The following yeast strains were used in this study: SEY6210: Mat a suc2- $\Delta 9$ ura3-52 leu2-3,113 his3- $\Delta 200$ trp1- $\Delta 901$ lys2-801 (Robinson et al., 1988), PS42-1A Mat a ura3 leu2 trp1 lys2 suc2- $\triangle 9$ pep4::HIS3 (Boehm et al., 1994), YMG1: PS42-1A vps33::URA3 (this study), YMG2: SEY6210 vps33::URA3 (this study). E. coli and DNA manipulations were performed according to standard procedures (Sambrook et al., 1989). Yeast manipulations were performed according to standard procedures (Sherman et al., 1986). Gene disruption by homologous recombination was performed as described previously (Rothstein, 1983). Yeast strains were grown in 1\% yeast extract (Gibco, Eggenstein, Germany), 2\% peptone 140 (Gibco, Eggenstein), 2\% glucose (YEPD), or in synthetic glucose medium (SD) supplemented as necessary (Rose et al., 1990). Solid media were prepared by adding $2 \%$ agar (Gibco, Eggenstein). Temperature sensitivity of vps33-mutants was assayed as described previously (Götte and Gallwitz, 1997). In brief, $5 \mu \mathrm{L}$ of a logarithmically growing culture of YMG1-transformants were applied to SD-LEU agar plates in serial 1:10 dilutions and incubated at the permissive $\left(25^{\circ} \mathrm{C}\right)$ and nonpermissive $\left(37^{\circ} \mathrm{C}\right)$ temperatures, respectively, for 3 days. Lithium acetate transformation of yeast cells was performed as described by Ito et al. (1983).

\section{Radiolabelling and immunoprecipitation}

Pulse-chase experiments were performed as described previously by Götte and Stadtbäumer (2002), using the anti CPY-antiserum described by Benli et al. (1996). In brief, single clones of YMG2 transformands were cultured until they reached the logarithmic growth phase in liquid medium. Cells were converted to spheroblasts using Zymolyase 100-T and metabolically labeled for $15 \mathrm{~min}$ with Tran ${ }^{35} \mathrm{~S}$-label at $30{ }^{\circ} \mathrm{C}$. CPY was immunoprecipitated using a specific antiserum either from the medium (external fraction: e) or from the spheroplast lysate (intracellular fraction: i) immediately after labelling ( 0 min chase) or after $30 \mathrm{~min}$ of chase with nonradioactive medium $(30 \mathrm{~min})$. After purification of protein A sepharose, the immunoprecipitated proteins were subjected to SDS-PAGE and autoradiography.

\section{SDS-PAGE and Western blotting}

SDS-PAGE and Western blotting were performed as described previously (Laemmli, 1970; Burnette, 1981). For steady-state Western blotting, yeast extracts were prepared by alkaline lysis followed by TCA precipitation as described (Benli et al., 1996). Antisera were provided by M. Benli (CPY, ALP, Benli et al., 1996) and Y. Anraku (PrA). Secondary horseradish-peroxidase-labeled anti-mouse or anti-rabbit IgG antibodies were from Amersham Buchler, Braunschweig, Germany. The ECL-system (Amersham Buchler, Braunschweig) was used for signal detection after 
Western blotting, followed by exposure on X-ray-film (Kodak, Rochester, NY). Antibodies were used at the following dilutions: anti-ALP: 1:2,000; anti-PrA: undiluted $\mathrm{mAb}$, secondary antibodies: 1:10,000.

\section{Vital staining}

Staining of yeast cells with the fluorescent dye CDCFDA was done exactly as described by Roberts et al. (1991). Cells were observed with a Zeiss Axiophot photomicroscope (Zeiss, Oberkochen, Germany) and photographed using Kodak T-Max400 film at $\mathrm{t}=15-30 \mathrm{~s}$ for fluorescence and $\mathrm{t}=0.75-1.5 \mathrm{~s}$ for Nomarski pictures.

\section{Results and discussion}

\section{Construction of a temperature-sensitive vps33 mutant strain}

A probe for VPS33 comprising codons 424-640 was amplified from genomic yeast DNA with specific PCR primers and used for colony hybridization after labeling with ${ }^{32} \mathrm{P}$. Screening of 19,000 colonies of a yeast genomic library (Dascher et al., 1991) in E.coli yielded two clones which hybridized under stringent conditions. Southernblotting and DNA-sequencing confirmed that one clone contained full-length VPS33. The VPS33 gene was subcloned into the SmaI site of pBluescriptIIKS+ as a blunt-ended ApaLI/AvrII-fragment (Figure 1a). The flanking polylinker sites BamHI and SalI were utilized to subclone VPS33 into the shuttle vectors pRS315 (CEN, LEU) and pRS325 (2 $\mu$, LEU; Sikorski and Hieter, 1989). In order to obtain vps33 deletion strains, the yeast strains SEY6210 and PS42-1A were transformed with a linearized EcoRI/BamHI-Fragment of the vector pMG19 (Figure 1b) and selected on SD-Ura agar plates. VPS33 codons 78-367 were replaced in vector pMG19 by a $1.1 \mathrm{kB}$ HindIIIFragment of the yeast $U R A 3$ gene. The correct integration of the construct was verified by a PCR reaction using genomic DNA of the respective strains as template (Figure 1c).

While both YMG1 (PS42-1A background) and YMG2 (SEY6210 background) mutant strains exhibited the highly fragmented vacuolar morphology of vps33 deletion strains (Banta et al., 1990; Wada et al., 1990) (see also Figure 2c), only YMG1 (vps33/pep4) exhibited a pronounced temperature sensitivity at $37{ }^{\circ} \mathrm{C}$ (see Figure 2a). Therefore, this strain was chosen for a search for temperature sensitivity suppressors. pep 4 strains have reduced vacuolar hydrolase activity due to the key role of proteinase A, which activates several vacuolar enzymes by proteolytic cleavage of their precursor forms (van den Hazel et al., 1996; Westphal et al., 1996). For the suppressor screening, a yeast genomic library in vector Yep13 (Dascher et al., 1991) was transformed into YMG1, followed by growth at $25^{\circ} \mathrm{C}$ for $24 \mathrm{~h}$ and a shift to $37^{\circ} \mathrm{C}$ for $48 \mathrm{~h}$. A control plate incubated at $25{ }^{\circ} \mathrm{C}$ allowed to calculate the transformation

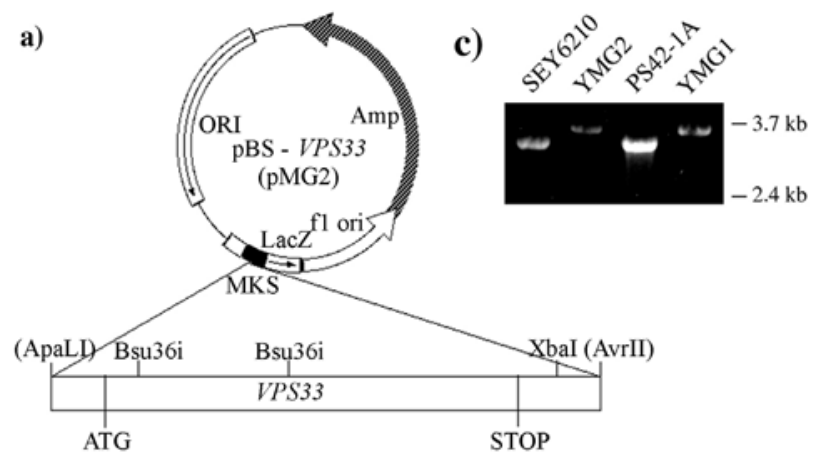

b)

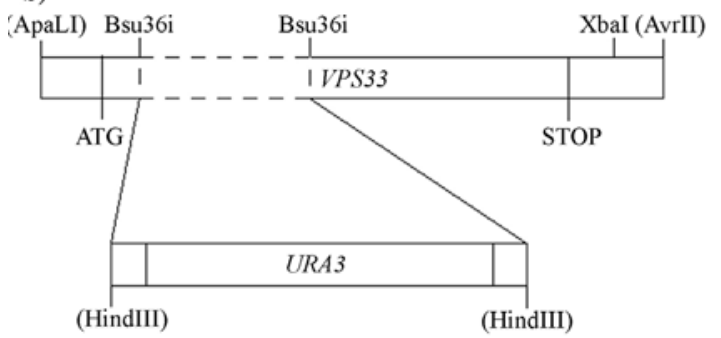

Figure 1 - Cloning of the VPS33 gene and deletion of VPS33 in the wild-type yeast strains SEY6210 and PS-42-1A. a) schematic drawing of the cloning strategy for VPS33 (see text for details). MKS = multicloning site; $\mathrm{ATG}=$ translation initiation codon; $\mathrm{STOP}=$ stopcodon; $\mathrm{Amp}=$ $\beta$-lactamase gene; ori $=$ origin of replication. b) schematic drawing of the pMG19 insert used for gene disruption of VPS33. pMG19 was created by cloning the blunt-ended HindIII fragment of the yeast URA3 gene into the blunt-ended Bsu36i sites of vector pMG2 (see Figure 1a). c) verification of VPS33 gene disruption by PCR. Genomic DNA was prepared from yeast strains SEY6210, PS42-1A, YMG1, and YMG2, and used as a template for a PCR reaction with VPS33-specific primers. The locations of the primers were $683 \mathrm{bp}$ upstream of the START-codon and $520 \mathrm{bp}$ downstream to the STOP-codon, resulting in the amplification of a $3.3 \mathrm{kB}$ fragment in wild-type cells and a $3.6 \mathrm{kB}$ fragment in vps 33 deletion mutants.

efficiency to 8,400 colonies, corresponding to $3.3 \times 10^{7}$ screened basepairs of the yeast genome. 33 transformants were capable of growing at $37^{\circ} \mathrm{C}$ on the original screening plates. Seventeen of these colonies were able to grow well in liquid culture at the nonpermissive temperature. The plasmids (pS1 to pS17) were isolated from these cultures, retransformed into and amplified in E.coli and used for a retransformation into vps33 mutant strains YMG1 (vps33/pep4) and YMG2 (vps33/PEP4). The sequence of the 5'- and 3' ends of the plasmid inserts was determined by DNA sequencing. In addition to the plasmids identified in the screening, $2 \mu$ plasmids containing the genes encoding the small transport GTPases Ypt6p and Ypt7p, as well as the yeast syntaxins Pep12p and Vam3p, were tested for suppressor activity. Like Vps33p, these proteins are involved in vesicular trafficking to the vacuole (for discussion, see Götte et al., 2000; Götte and Stadtbäumer, 2002). While strain YMG1 was used to confirm the suppression of temperature sensitivity, strain YMG2 was used to test for complementation of the vesicular trafficking and vacuolar morphology defects of vps33 deletion mutants. The suppressor plasmids could be divided into three categories 
(I-III) (Figure 2b), which differed in the degree of suppression of vps33 mutant phenotypes.

\section{Suppression of the growth defect at $37^{\circ} \mathrm{C}$}

The suppression of the growth defect was determined in a drop test using different dilutions of yeast cultures of a defined $\mathrm{OD}_{600}$ (see Figure 2a and Götte and Gallwitz, a)

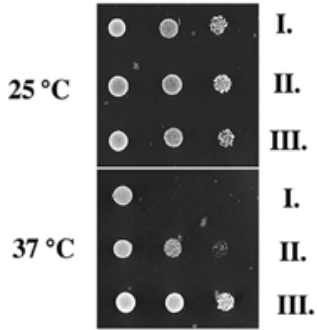

c)
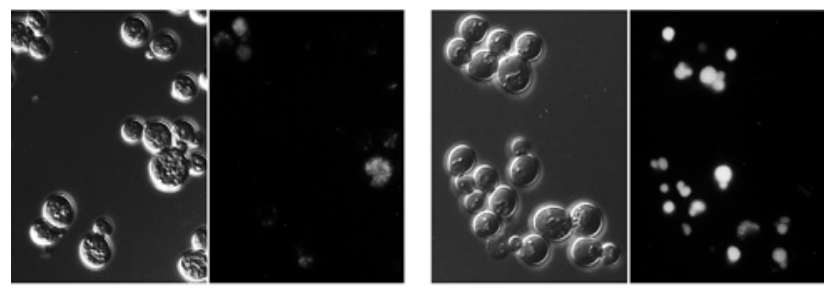

I. + II. b)

\begin{tabular}{|l|l|l|}
\hline \multicolumn{1}{|c|}{ I. } & \multicolumn{1}{|c|}{ II. } & \multicolumn{1}{c|}{ III. } \\
\hline PEP12 & pS2 & VPS33 \\
VAM3 & pS3 & pS1 \\
YPT6 & pS4 & pS5 \\
YPT7 & pS10 & pS6 \\
pS7 & pS12 & pS9 \\
pS8 & pS15 & pS13 \\
pS11 & pS16 & \\
pS14 & pS17 & \\
pRS315 & & \\
\hline
\end{tabular}

III.
Figure 2 - Suppression of temperature sensitivity for growth and vacuole fragmentation in vps33 mutants. VPS33 mutant strains YMG1 and YMG2 were transformed with the plasmids indicated in $2 b$ ). Three classes of suppressors (I-III), which displayed similar degrees of suppression, were identified. a) Suppression of the ts-growth defect of $v p s 33$ deletion strain YMG1. Agar plates containing serial dilutions of logarithmically growing YMG1-transformants were incubated at the permissive $\left(25^{\circ} \mathrm{C}\right)$ and nonpermissive $\left(37^{\circ} \mathrm{C}\right)$ temperatures, respectively, for 3 days. Plasmids of category I (cf. b) did not support growth at $37{ }^{\circ} \mathrm{C}$ after retransformation. Plasmids of category II allowed for growth, whereas plasmids of category III supported growth similar to permissive conditions. c) Suppression of vacuole fragmentation of the vps 33 mutant strain YMG2. The vacuoles of YMG2 were stained with the fluorescent dye CDCFDA and viewed with Nomarski-DIC optics (left panels) or fluorescence optics (right panels), respectively. Class I and class II plasmids could not suppress vacuole fragmentation, whereas class III plasmids restored wild-type vacuole morphology. Suppressor categories I-III are represented by control vectors pRS315 (cat. I, part a), pS3 (cat. II), and pS9 (cat. III, VPS33), respectively.
1997). After retransformation, the PEP12 and YPT6 genes, as well as 4 putative suppressor plasmids of the first round of screening, were not capable of supporting growth of vps33 mutants at the nonpermissive temperature (category I inserts). In contrast, plasmids containing the VPS33 gene allowed for growth at $37^{\circ} \mathrm{C}$, as expected. Restriction analysis and DNA-sequencing revealed the presence of VPS33 in 5 suppressor plasmids (category III inserts, see Table 1). The genes encoded by the plasmid inserts of category II had an intermediate effect: they allowed for growth of vps33 cells at the nonpermissive temperature, however, the cells did not grow as well as YMG1 cells transformed with VPS33 (Figure 2a). Since the temperature sensitivity of $v p s$-mutants can be seen as a secondary effect of the respective mutations, we tested for suppression of more specific phenotypes of the vps33 deletion, using the YMG2 strain.

\section{Test for suppression of the aberrant vacuolar morphology of vps33 mutants}

The most prominent morphological aberration of vps33 mutants is the absence of a typical vacuole (Banta et al., 1990; Wada et al., 1990). Even after vacuole staining with fluorescent dyes, only a few fluorescent spots can be observed in vps33 cells (Kitamoto et al., 1988). Vacuole staining of YMG2-transformants with the fluorescent dye CDCFDA revealed that only plasmids containing the VPS33 gene (category III) were capable of restoring the vacuole morphology to a wild-type appearance (Figure 2c). The other ts-suppressor- plasmids, as well as $2 \mu$ plasmids containing the VAM3 and YPT7 genes, were unable to restore wild-type morphology. In Nomarski differential interference contrast (DIC) pictures, the vacuole showed a highly fragmented appearance and only little staining with CDCFDA in fluorescence microscopy (Figure 2c).

\section{Test for suppression of vacuolar enzyme maturation and sorting defects in vps33 mutants}

VPS33 deletion mutants display severe sorting defects of the vacuolar enzymes carboxypeptidase Y (CPY) and proteinase $\mathrm{A}(\operatorname{PrA})$, as well as maturation defects of these enzymes and of the enzyme alkaline phosphatase (ALP) (Banta et al., 1990; Wada et al., 1990). We tested for suppression of these defects by the ts-suppressor plasmids using CPY-, ALP- and PrA-antisera in Western blots of

Table 1 - Sequence analysis of category II suppressors for temperature sensitivity of vps33 strain YMG1 (cf Mewes et al. 1997, Cherry et al. 1998).

\begin{tabular}{llll}
\hline Suppressor & Chromosome & Location $(\mathrm{bp})$ & Open reading frames \\
\hline $\mathrm{pS} 2$ & $\mathrm{IV}$ & $613036-618580$ & YDR084c, AFR1, SSS1, RRP1 \\
$\mathrm{pS} 3, \mathrm{pS} 17$ & $\mathrm{XI}$ & $420627-424892$ & UFD4 (C-terminus) \\
$\mathrm{pS} 4$ & $\mathrm{X}$ & $470010-471904$ & BNA1, YJR024c \\
$\mathrm{pS} 10$ & $\mathrm{XIV}$ & $289050-293350$ & UBP10, YNL184c, MRPL19 \\
$\mathrm{pS} 12, \mathrm{pS} 15$ & $\mathrm{~V}$ & $508369-512841$ & CHD1 (C-terminus), PAB1 \\
S16 & $\mathrm{XV}$ & $178730-184167$ & IRA2 (C-terminus), REX4, YOL079w, YOL078w (N-terminus) \\
\hline
\end{tabular}


whole cell extracts of YMG2 transformants. In a part of the transformants, a detailed analysis of the maturation kinetics of CPY was performed in pulse-chase immunoprecipitation experiments (Figure 3). Only ts-suppressor plasmids containing the VPS33 gene were capable of suppressing the maturation- and sorting defects of the respective enzymes. Therefore, the ts-suppressor plasmids were not suppressors of the vesicular protein transport defects of the vps33 mutants, but exerted the suppression of temperature sensitivity through an alternative mechanism (see discussion below).

\section{a)}

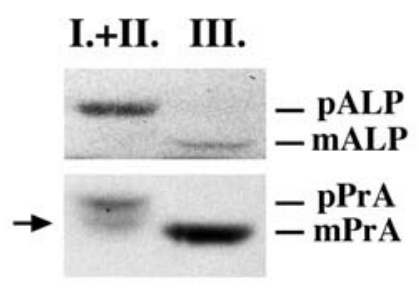

b)

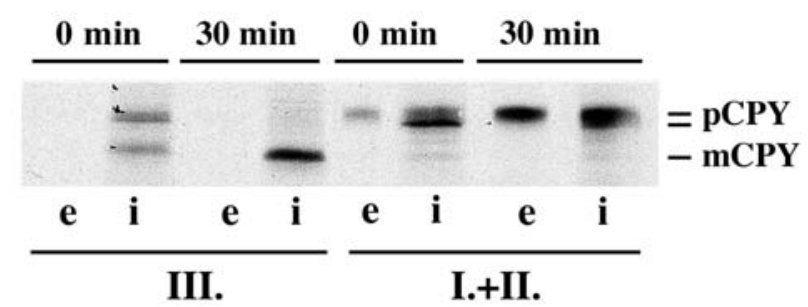

Figure 3 - Influence of suppressor plasmids on the processing of vacuolar enzymes in the vps33 mutant strain YMG2. a) Processing of vacuolar enzymes in YMG2-transformants under steady-state conditions. Whole cell extracts of YMG2 cells transformed with the plasmids indicated in Figure $2 \mathrm{~b}$ were subjected to SDS-PAGE and Western blotting. The blot membranes were probed with anti-ALP (upper panel) or anti-PrA antibodies, followed by incubation with POD-coupled secondary antibodies and enhanced chemoluminescence detection. Only category III plasmids allowed for a maturation of the vacuolar enzymes. $m=$ mature form of enzymes; $p=$ precursor form of enzymes; arrow = extracellular, autocatalytically processed form of PrA (van den Hazel et al., 1996). b) Sorting and kinetics of carboxypeptidase Y (CPY) maturation (cf. Benli et al., 1996). The vps33 mutant strain YMG2 was transformed with the plasmids indicated in Figure $2 \mathrm{~b}$, and spheroplasts of single clones were metabolically labeled with $\operatorname{Tran}^{35} \mathrm{~S}$-label. CPY was immunoprecipitated using a specific antiserum either from the medium (external fraction: e) or from the spheroplast lysate (intracellular fraction: i) immediately after labeling ( 0 min chase) or after $30 \mathrm{~min}$ of chase with nonradioactive medium (30 min). Mature and precursor forms of CPY were detected by autoradiography following SDS-PAGE. Suppressor plasmid pS9, containing the VPS33 gene is shown representing category III inserts. Suppressor plasmid pS2 containing ORFs YDR083w-YDR087c is shown representing category I and II inserts. Only category III inserts were capable of suppressing the enzyme maturation/sorting defects of the vps 33 mutant strain YMG2, resulting in the appearance of the mature form of CPY after a 30 min chase, and the absence of CPY precursor forms in the extracellular fraction. $\mathrm{m}=$ mature form of $\mathrm{CPY} ; \mathrm{p}=$ precursor forms of $\mathrm{CPY}$. (upper band: Golgi-modified form; lower band: ER-modified form); $\mathrm{i}=$ intracellular $\mathrm{CPY} ; \mathrm{e}=$ secreted $\mathrm{CPY}$.

\section{Analysis of suppressor plasmids}

The suppressor plasmids of categories I-III were subjected to restriction enzyme analysis and partial DNA sequencing of the Yep13-inserts. Plasmids pS7, pS8, pS11, and pS14 (category I) were not capable of ts-suppression after retransformation into YMG1 and thus not analyzed further. The sequence information of the remaining plasmid inserts was compared to the genome of Saccharomyces cerevisiae using the MIPS and SGD databases (Mewes et al., 1997; Cherry et al., 1998). Plasmids pS1, pS5, pS6, pS9, and pS13 (category III) contained the original VPS33 gene. The sequence information on the ts-suppressor plasmids of category II is given in Table 1.

Although the vps33 deletion was created in a pep4 background in the YMG1 strain, the PEP4 gene was not found as a suppressor in this screening, indicating either its absence in the plasmid library or a negative effect of PEP 4 overexpression on growth at an elevated temperature. Sequence analysis of the category II inserts did not reveal any candidate genes belonging to protein families well-known for involvement in vesicular trafficking, like the $\mathrm{Ypt} / \mathrm{Rab}$ or SNARE proteins (Götte and Fischer von Mollard, 1998; Götte et al., 2000). This is in accordance with the lack of complementing activity regarding the vesicular trafficking phenotype of the vps33 mutant. Two pairs of suppressor plasmids contained the same inserts and were isolated twice (see Table 1).

\section{High expression of the ubiquitin ligase Ufd4p suppresses temperature sensitivity of the YMG1 strain}

The insert of plasmids pS3 and pS17 contained a fragment of chromosome XI ranging from bp 420627 to 424892. This chromosomal region harbors the major part of the UFD4 gene (YKL010c), encoding a ubiquitin-protein ligase (Johnson et al., 1995; Xie and Varshavsky, 2000) as the only open reading frame (ORF) on the plasmid. The suppressor insert encodes the Ufd4 protein starting at amino acid 214. The resulting protein contains both HECT domains, which are responsible for the ubiquitin ligase activity of Ufd $4 p$ (Johnson et al., 1995). The respective ATG codon is in frame with the ORF, and the 5' end contains a TATA sequence. The Ufd4 protein is physically associated with the 26S proteasome (Xie and Varshavsky, 2000), and was recently found in association with the ubiquitinconjugating enzyme Ubc4p and the medium subunit of the clathrin-associated complex, Apm1p, in a mass spectrometry study of yeast protein complexes (Ho et al., 2002). Proteolysis regulation by the ubiquitin pathway is part of a cellular stress response (Hershko and Ciechanover, 1998). However, recent findings by several laboratories have established a link between the ubiquitin/proteasome pathway and vesicular trafficking along the endocytic pathway:

Ubiquitin can act as an endocytosis signal in yeast (Rotin et al., 2000; Dupre and Haguenauer-Tsapis, 2001; 
Polo et al., 2002). Proteasome inhibitor studies in transfected mammalian cells had already suggested that the ubiquitin-proteasome pathway is involved in an endosomal sorting step of selected membrane proteins to lysosomes (van Kerkhof et al., 2001). Yeast ubiquitin ligases localize to multiple sites along the endocytic pathway (Wang et al., 2001; Shin et al., 2001), and ubiquitin acts as a sorting signal for a subclass of transmembrane proteins into invaginating endosomal vesicles and multivesicular bodies (Reggiori and Pelham, 2001, 2002): Carboxypeptidase S and other membrane proteins containing polar residues exposed to the lipid bilayer are sorted to multivesicular bodies and the yeast vacuole depending on the ubiquitin ligase activity of the Golgi-resident Tul1 protein. The Vps33 protein is known to be involved in both vesicular trafficking steps. Ufd $4 p$ could be a further member of the growing group of ubiquitin ligases involved in marking proteins for targeting to vacuolar/endosomal compartments and in quality control along vesicular trafficking pathways. Its identification in a complex with Apm1p (Ho et al., 2002) might indicate that, like Apm1p, Ufd4p could be involved in protein sorting at a late Golgi compartment (Stepp et al., 1995) (Figure 4).

\section{Sequence analysis of candidate ORFs encoded by suppressor plasmids}

Sequence analysis of the remaining suppressor plasmids revealed that, in contrast to $\mathbf{p S 3}$ and $\mathbf{p S 1 7}$, these plasmids contained more than one ORF.

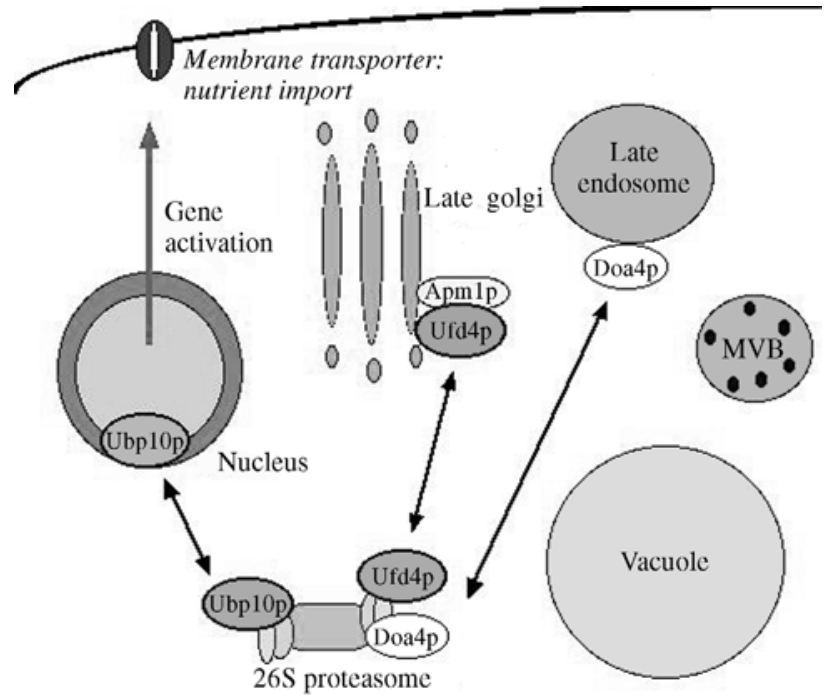

Figure 4 - Possible roles of the ubiquitin pathway enzymes Ufd $4 p$ and Ubp10p in vacuolar/endosomal trafficking and protein degradation (see text). Both Ufd4p and Ubp10p promote protein degradation via the proteasome. The ubiquitin ligase Ufd4p might act along the endocytic/Vps pathway, possibly by association with Apm1p. Like Doa4p, the deubiquitinating enzyme Ubp10p could reversibly associate with a compartment along the endocytic route. Alternatively, nuclear Ubp10p/Dot4p could activate genes involved in nutrient utilization. This process, as well as facilitated vacuolar or proteasomal protein degradation, would alleviate the stress conditions of the vps33 mutant strain YMG1 at the nonpermissive temperature. $\mathrm{MVB}=$ multivesicular body .
The insert of suppressor plasmid pS10 comprises bp 289050-293350 of chromosome XIV. Three complete ORFs are found in this chromosomal region: YNL084c is a hypothetical ORF of unknown function, which does not contain any well-characterized functional domains. YNL084c null mutants are viable (Winzeler et al., 1999). The neighboring ORF YNL185c encodes the Mrp119 protein, a mitochondrial ribosomal protein of the large subunit (Graack and Wittmann-Liebold, 1998). The most likely candidate for the suppressor activity of pS10 is encoded by UBP10/DOT4 (Kahana and Gottschling, 1999; Kahana, 2001), the gene for a ubiquitin-processing protease. Ubp proteins allow for a recycling of ubiquitin, thus promoting protein degradation via the ubiquitin/proteasome pathway (Voges et al., 1999). Kahana (2001) has demonstrated that Dot $4 p$ regulates nutrient uptake, suggesting that Dot $4 p$ overexpression might lead to an upregulation of genes involved in nutrient transport processes. Most interestingly, the vps33 mutation can act as an extragenic suppressor of the doa4-1 mutation (Amerik et al., 2000). DOA4 encodes another deubiquitinating enzyme, which reversibly localizes with the late endosome. It is required for rapid degradation of ubiquitin-proteasome pathway substrates. Apart from vps33, several class E VPS genes were identified in the screen for extragenic suppressors of doa4-1 (Amerik et al. 2000). Class E Vps proteins are also required for ubiquitin-dependent sorting into the multivesicular body (Katzman et al., 2001). As a deubiquitinating enzyme, Ubp10p/Dot4p would fall into the same functional category as Doa4p and could thus play a comparable role, maybe at a different trafficking step (Figure 4).

The insert of suppressor plasmids pS12 and pS15 contained bp 508369-512841 of yeast chromosome V. It comprises the 3' end of the CHD1 gene (YER164w) encoding a transcriptional regulator and the complete ORF of the poly-A-binding protein $P A B 1$ (YER165w). PAB1 physically interacts with the hsp70 homologue Ssa, and is strongly upregulated under heat-shock conditions (Gasch et al., 2000; Horton et al., 2001). Pablp binds to the translation intitiation complex and influences mRNA stability (Vilela et al., 2000; Morrissey et al., 1999; Mangus et al., 1998). Most interestingly, $P A B 1$ has recently been identified as a multicopy suppressor for a temperature-sensitive tif5-1A mutant yeast strain at an elevated temperature (Valentini et al., 2002): In this mutant of the eukaryotic translation initiation factor eIF5A, defects in degradation of short-lived mRNAs are noted, and the authors suggest that iIF5A may also be involved in ribosomal synthesis and in the WSC/PKC1 signaling pathway for cell wall integrity.

The suppressor plasmid $\mathbf{p S 2}$ contained 4 ORFs spanning bp 613036-618580 of chromosome IV: YDR084c is an ORF of unknown function lacking well-known structural motifs, and the deletion of YDR084c does not influence viability (Winzeler et al., 1999). The neighboring $A F R 1$ (YDR085c) gene product regulates alpha-factor re- 
ceptor signaling and induction of morphogenesis during conjugation (Konopka, 1993; Davis et al., 1998). AFR1 mRNA is highly induced upon a temperature shift to $37^{\circ} \mathrm{C}$ under several varying conditions (Gasch et al., 2000). Interestingly, Gga1p, a gene product involved in trafficking from the Golgi apparatus to the vacuole (Hirst et al., 2000), showed a very similar stress response pattern in the study by Gasch et al. (2000). However, the significance of this finding is not clear. The high induction of AFR1 under heat shock conditions makes it a candidate for the suppressor activity of the pS2 insert. In addition, the SSS1 (YDR086c) gene was found on the pS2 insert. The suppressor of sec61, Sss1p, is involved in the transfer of secretory precursors through the ER membrane (Esnault et al., 1993). Overexpression of SSS1 restores translocation in sec $61 \mathrm{mu}-$ tants, while depletion of Sss1p results in accumulation of secretory and membrane proteins devoid of posttranslational modification. One could speculate that a more efficient transport of proteins into the ER might compensate for some of the stress conditions exerted under heat shock conditions in vps 33 mutants. Thus, both AFR1 and SSS1 are candidates for the suppressor activity of pS2. The RRP1 gene (YDR087c) is the final ORF found on the $\mathrm{pS} 2$ insert. Its gene product is involved in the processing of rRNA precursors into mature rRNAs (Fabian and Hopper, 1987), and is not a likely suppressor candidate.

pS4 comprises bp 470010-471904 of chromosome X, including the major part of ORF YJR024c, truncated at the 3' end, and BNA1/HAD1 (YJR025c). While the function of YJR024c is not yet clear, BNA1 has been shown to encode 3-hydroxyanthranilic acid dioxygenase (Kucharzyk et al., 1998). BNA1 is upregulated under heat stress conditions (Gasch et al., 2000), and its deletion results in upregulation of a large number of genes involved in carbon metabolite utilization and transport, the cell cycle, and amino acid metabolism (Bernstein et al., 2000). Bnalp is part of a feedback loop modulating the histone deacytylase Rpd3p, and seems to play a role in telomeric silencing (Sandmeier et al., 2002). Thus, changes in Bnalp levels will influence the expression of a large number of genes, which defies any easy interpretation of our findings.

Suppressor plasmid $\mathbf{p S 1 6}$ contains an insert ranging from bp 178730 to bp 184167 of chromosome XV. This insert contains the $3^{\prime}$ ' end of the gene encoding the RAS-GTPase activating protein Ira2p (Tanaka et al., 1990). The complete ORF YOL080c, encoding REX4, a member of the RNA 3'-5' exonuclease family (Moser et al., 1997), is also present on the suppressor insert. YOL079w, a hypothetical ORF encoded on the Crick strand, overlaps with YOL080c on the Watson strand of chromosome XV. Only a C-terminally truncated fragment of the ORF YOL078w is present on the suppressor plasmid $\mathrm{pS} 16$. Deletion of this ORF of unknown function leads to lethality (Winzeler et al., 1999). YOL078w mRNA is significantly induced under restricted temperature shift condi- tions (temperature shift from $29^{\circ} \mathrm{C}$ to $33{ }^{\circ} \mathrm{C}$ for $30 \mathrm{~min}$; Gasch et al., 2000). The translated amino acid sequence displays weak homology to the SAP kinase interacting protein 1 of Schizosaccharomyces pombe (Wilkinson et al., 1999), however, the significance of this finding is not yet clear. At present, it is difficult to determine which mechanism might underlie the ts-suppressor activity of pS16 on the vps 33 mutant strain YMG1.

\section{Concluding remarks}

In summary, two groups of suppressor candidates arise: One group includes candidate genes which are part of a more general heat shock/stress response (PABl, AFRl, $S S S 1, B N A 1)$. The respective gene products are known to be upregulated under heat shock conditions, or to induce a secondary upregulation of a whole group of other gene products. Further experiments are needed to identify the ORFs which harbor the suppressor activity. At present knowledge, none of the gene products identified appears to be involved in vesicular trafficking to the yeast vacuole.

The second group of ts-suppressors consists of the ubiquitin ligase Ufd4p and a candidate gene, UBP10, which also acts along the ubiquitin/proteasome pathway. The isolation of genes encoding ubiquitin-pathway enzymes supports recent observations indicating a functional link between the ubiquitin system and vacuolar protein sorting/endocytosis. Under the restrictive conditions exerted in the vps 33 suppressor screening, high expression of Ufd $4 p$ or Ubp 10p could lead to a more efficient utilization of alternative trafficking routes to degradative compartments. In addition, an increase in protein degradation in the proteasome can be envisaged. Both effects would compensate for impaired vacuolar protein degradation in the vps 33 mutant.

Our results suggest that Ufd $4 p$ and possibly Ubp $10 p$ are two new candidates for the growing family of ubiquitin-processing enzymes involved in trafficking along the endocytic/Vps pathway.

\section{Acknowledgements}

Funding was provided by the Max-Planck Society, Protogeneia, Inc., and the SmithKlineBeecham Foundation. The author wants to thank Ms Rita Schmitz-Salue for technical assistance, H.D. Schmitt for providing the Yep13 library (Dascher et al., 1991) and the yeast strain PS42-1A (Boehm et al., 1996), M. Benli and Y. Anraku for providing valuable antibodies, as well as D. Gallwitz, D. Gottschling and S.D. Bisbas for discussions.

\section{References}

Amerik AY, Nowak J, Swaminathan, S and Hochstrasser M (2000) The Doa4 deubiquitinating enzyme is functionally linked to the vacuolar protein-sorting and endocytic pathways. Mol Biol Cell 11:3365-3380. 
Banta LM, Vida TA, Herman PK and Emr SD (1990) Characterization of yeast Vps33p, a protein required for vacuolar protein sorting and vacuole biogenesis. Mol Cell Biol 10:4638-4649.

Benli M, Döring F, Robinson DG, Yang X and Gallwitz D (1996) Two GTPase isoforms, Ypt31p and Ypt32p, are essential for Golgi function in yeast. EMBO J 15:6460-6475.

Bernstein BE, Tong JK and Schreiber SL (2000) Genomewide studies of histone deacetylase function in yeast. Proc Natl Acad Sci USA 97:13708-13713.

Boehm J, Ulrich HD, Ossig R and Schmitt HD (1994) Kex2-dependent invertase secretion as a tool to study the targeting of transmembrane proteins which are involved in ER - Golgi transport in yeast. EMBO J 13:3696-3710.

Burnette WN (1981) "Western blotting”: electrophoretic transfer of proteins from sodium dodecyl sulfate-polyacrylamide gels to unmodified nitrocellulose and radiographic detection with antibody and radioiodinated protein A. Anal Biochem 112:195-203.

Cherry JM, Adler C, Ball C, Chervitz SA, Dwight SS, Hester ET et al. (1998) SGD: Saccharomyces Genome Database. Nucleic Acids Res 26:73-80.

Dascher C, Ossig R, Gallwitz D and Schmitt HD (1991) Identification and structure of four yeast genes (SLY) that are able to suppress the functional loss of $Y P T 1$, a member of the RAS superfamily. Mol Cell Biol 11:872-885.

Davis C, Dube P and Konopka JB (1998) Afrlp regulates the Saccharomyces cerevisiae alpha-factor receptor by a mechanism that is distinct from receptor phosphorylation and endocytosis. Genetics 148:625-635.

Dupre S and Haguenauer-Tsapis R (2001) Deubiquitination step in the endocytic pathway of yeast plasma membrane proteins: crucial role of Doa4p ubiquitin isopeptidase. Mol Cell Biol 21:4482-4494.

Esnault Y, Blondel MO, Deshaies RJ, Schekman R and Kepes F (1993) The yeast SSSI gene is essential for secretory protein translocation and encodes a conserved protein of the endoplasmic reticulum. EMBO J 12:4083-4093.

Fabian GR and Hopper AK (1987) RRP1, a Saccharomyces cerevisiae gene affecting rRNA processing and production of mature ribosomal subunits. J Bacteriol 169:1571-1578.

Gasch AP, Spellman PT, Kao CM, Carmel-Harel O, Eisen MB, Storz G et al. (2000) Genomic expression programs in the response of yeast cells to environmental changes. Mol Biol Cell 11:4241-4257.

Glickman MH and Ciechanover A (2002) The ubiquitinproteasome proteolytic pathway: destruction for the sake of construction. Physiol Rev 82:373-428.

Götte M and Fischer von Mollard G (1998) A new beat for the SNARE drum. Trends Cell Biol 8:215-218.

Götte M and Gallwitz D (1997) High expression of the yeast syntaxin-related Vam3 protein suppresses the protein transport defects of a pep12 null mutant. FEBS Lett 411:48-52.

Götte M and Lazar T (1999) The ins and outs of yeast vacuole trafficking. Protoplasma 209:9-18.

Götte M, Lazar T, Yoo J-S, Scheglmann D and Gallwitz D (2000) The full complement of yeast Ypt/Rab-GTPases and their involvement in exo- and endocytic trafficking. In: Hilderson HJ and Fuller S (eds) Subcellular Biochemistry v. 34. Fusion of biological membranes and related problems Kluwer Academic/Plenum Publishers, New York, pp 133-174.

Götte M and Stadtbäumer A (2002) Heterologous expression of Syntaxin 6 in Saccharomyces cerevisiae. Biol Res 35:347-357.

Graack HR and Wittmann-Liebold B (1998) Mitochondrial ribosomal proteins (MRPs) of yeast. Biochem J 329:433-448.

Hershko A and Ciechanover A (1998) The ubiquitin system. Annu Rev Biochem 76:425-479.

Hirst J, Lui WW, Bright NA, Totty N, Seaman MN and Robinson MS (2000) A family of proteins with gamma-adaptin and VHS domains that facilitate trafficking between the trans-Golgi network and the vacuole/lysosome. J Cell Biol 149:67-80.

Ho Y, Gruhler A, Heilbut A, Bader GD, Moore L, Adams SL et al. (2002) Systematic identification of protein complexes in Saccharomyces cerevisiae by mass spectrometry. Nature 415:180-183.

Horton LE, James P, Craig EA and Hensold JO (2001) The yeast hsp70 homologue Ssa is required for translation and interacts with Sis1 and Pab1 on translating ribosomes. J Biol Chem 276:14426-14433.

Ito H, Fukuda Y, Murata K and Kimura A (1983) Transformation of intact yeast cells treated with alkali cations. J Bacteriol 153:163-168.

Jacquemin-Faure I, Thomas D, Laporte J, Cibert C and Surdin-Kerjan Y (1994) The vacuolar compartment is required for sulfur amino acid homeostasis in Saccharomyces cerevisiae. Mol Gen Genetics 244:519-529.

Johnson ES, Ma PCM, Ota IM and Varshavsky A (1995) A proteolytic pathway that recognizes ubiquitin as a degradation signal. J Biol Chem 270:17442-17456.

Kahana A (2001) The deubiquitinating enzyme Dot4p is involved in regulating nutrient uptake. Biochem. Biophys Res Commun 282:916-920.

Kahana A and Gottschling DE (1999) DOT4 links silencing and cell growth in Saccharomyces cerevisiae. Mol Cell Biol 19:6608-6620.

Katzmann DJ, Babst M and Emr SD (2001) Ubiquitin-dependent sorting into the multivesicular body pathway requires the function of a conserved endosomal protein sorting complex, ESCRT-I. Cell 106:145-155.

Kitamoto K, Yoshizawa K, Ohsumi Y and Anraku Y (1988) Mutants of Saccharomyces cerevisiae with defective vacuolar function. J Bacteriology 170:2687-2691.

Klionsky DJ, Herman PJ and Emr SD (1990) The fungal vacuole:composition, function, and biogenesis. Microbiol Rev 54:266-292.

Konopka JB (1993) AFRl acts in conjunction with the alphafactor receptor to promote morphogenesis and adaptation. Mol Cell Biol 13:6876-6888.

Kucharczyk R, Zagulski M, Rytka J and Herbert CJ (1998) The yeast gene YJR025c encodes a 3-hydroxyanthranilic acid dioxygenase and is involved in nicotinic acid biosynthesis. FEBS Lett 424:127-130.

Laemmli UK (1970) Cleavage of structural proteins during the assembly of the head of bacteriophage T4. Nature 227:680685.

Losko S, Kopp F, Kranz A and Kölling R (2001) Uptake of the ATP-binding cassette $(\mathrm{ABC})$ transporter Ste6 into the yeast 
vacuole is blocked in the doa4 mutant. Mol Biol Cell 12:1047-1059.

Mangus DA, Amrani N and Jacobson A (1998) Pbp1p, a factor interacting with Saccharomyces cerevisiae poly(A)-binding protein, regulates polyadenylation. Mol Cell Biol 18:7383-7396.

Mewes HW, Albermann K, Heumann K, Liebl S and Pfeiffer F (1997) MIPS: A database for protein sequences, homology data and yeast genome information. Nucl Acid Res 25:28-30.

Morrissey JP, Deardorff JA, Hebron C and Sachs AB (1999) Decapping of stabilized, polyadenylated mRNA in yeast pab1 mutants. Yeast 15:687-702.

Moser MJ, Holley WR, Chatterjee A and Mian IS (1997) The proofreading domain of Escherichia coli DNA polymerase I and other DNA and/or RNA exonuclease domains. Nucleic Acids Res 25:5110-5118.

Peterson MR and Emr SD (2001) The class C vps complex functions at multiple steps along the yeast endocytic pathway. Traffic 3:37-49.

Polo S, Sigismund S, Faretta M, Guidi M, Capua MR, Bossi G et al. (2002) A single motif responsible for ubiquitin recognition and monoubiquitination in endocytic proteins. Nature 416:451-455.

Raymond CK, Howald-Stevenson I, Vater CA and Stevens TH (1992) Morphological classification of the yeast vacuolar protein sorting mutants. Evidence for a prevacuolar compartment in class E vps mutants. Mol Biol Cell 3:1389-1402.

Reggiori F and Pelham HR (2001) Sorting of proteins into multivesicular bodies: ubiquitin-dependent and -independent targeting. EMBO J 20:5176-5186.

Reggiori F and Pelham HR (2002) A transmembrane ubiquitin ligase required to sort membrane proteins into multivesicular bodies. Nat Cell Biol 4:117-123.

Roberts CJ, Raymond CK, Yamashiro CT and Stevens TH (1991) Methods for studying the yeast vacuole. In Guthrie Ch and Fink GR (eds) Guide to yeast genetics and Molecular Biology. Meth Enz 194:644-661.

Robinson JS, Klionsky DJ, Banta LM and Emr SD (1988) Protein sorting in Saccharomyces cerevisiae: isolation of mutants defective in the delivery and processing of multiple vacuolar hydrolases. Mol Cell Biol 8:4936-4948.

Rose MD, Winston F and Hieter P (1990) Methods in Yeast Genetics. A Laboratory Course Manual. Cold Spring Harbor Laboratory Press, Cold Spring Harbor, NY.

Rothman JH, Howald I and Stevens TH (1989) Characterization of genes required for protein sorting and vacuolar function in the yeast Saccharomyces cerevisiae. EMBO J 8:20572065.

Rothstein RJ (1983) One-step gene disruption in yeast. Meth Enzymol 101:202-211.

Rotin D, Staub O and Haguenauer-Tsapis R (2000) Ubiquitination and endocytosis of plasma membrane proteins: role of Nedd4/Rsp5p family of ubiquitin-protein ligases. J Membr Biol 176:1-17.

Sambrook J, Fritsch EF and Maniatis T (1989) Molecular Cloning: A Laboratory Manual, Second Edition, Cold Spring Harbor Laboratory Press, Cold Spring Harbor, NY.

Sandmeier JJ, Celic I, Boeke JD and Smith JS (2002) Telomeric and rDNA silencing in Saccharomyces cerevisiae are de- pendent on a nuclear $\mathrm{NAD}(+)$ salvage pathway. Genetics 160:877-889.

Sato TK, Rehling P, Peterson MR and Emr SD (2000) Class C Vps protein complex regulates vacuolar SNARE pairing and is required for vesicle docking/fusion. Mol Cell 6:661-671.

Seals DF, Eitzen G, Margolis N, Wickner WT and Price A (2000) A Ypt/Rab effector complex containing the Sec1 homolog $\mathrm{Vps} 33 \mathrm{p}$ is required for homotypic vacuole fusion. Proc Natl Acad Sci USA 97:9402-9407.

Sherman F, Fink GR and Hicks JR (1986) Methods in Yeast Genetics: a Laboratory Manual. Cold Spring Harbor Laboratory, Cold Spring Harbor, NY.

Shin ME, Ogburn KD, Varban OA, Gilbert PM and Burd CG (2001) FYVE domain targets Piblp ubiquitin ligase to endosome and vacuolar membranes. J Biol Chem 276:41388-41393.

Sikorski RS and Hieter P (1989) A system of shuttle vectors and yeast host strains designed for efficient manipulation of DNA in Saccharomyces cerevisiae. Genetics 122:19-27.

Stepp JD, Pellicena-Palle A, Hamilton S, Kirchhausen T and Lemmon SK (1995) A late Golgi sorting function for Saccharomyces cerevisiae Apm1p, but not for Apm2p, a second yeast clathrin AP medium chain-related protein. Mol Biol Cell 6:41-58.

Tanaka K, Nakafuku M, Satoh T, Marshall MS, Gibbs JB, Matsumoto K et al. (1990) S. cerevisiae genes IRAI and $I R A 2$ encode proteins that may be functionally equivalent to mammalian ras GTPase activating protein. Cell 60:803-807.

Valentini SR, Casolari JM, Oliveira CC, Silver PA and McBride AE (2002) Genetic interactions of yeast eukaryotic translation initiation factor 5A (eIF5A) reveal connections to poly(A)-binding protein and protein kinase $\mathrm{C}$ signaling. Genetics 160:393-405.

van den Hazel HB, Kielland-Brandt MC and Winther JR (1996) Biosynthesis and function of yeast vacuolar proteases. Yeast 12:1-16.

van Kerkhof P, Alves dos Santos CM, Sachse M, Klumperman J, Bu G and Strous GJ (2001) Proteasome inhibitors block a late step in lysosomal transport of selected membrane but not soluble proteins. Mol Biol Cell 12:2556-2566.

Vilela C, Velasco C, Ptushkina M and McCarthy JE (2000) The eukaryotic mRNA decapping protein Dcp1 interacts physically and functionally with the eIF4F translation initiation complex. EMBO J 19:4372-4382.

Voges D, Zwickl P and Baumeister W (1999) The 26S proteasome: a molecular machine designed for controlled proteolysis. Annu Rev Biochem 68:1015-1068.

Wada Y, Kitamoto K, Kanbe T, Tanaka K and Anraku Y (1990) The SLP1 gene of Saccharomyces cerevisiae is essential for vacuolar morphogenesis and function. Mol Cell Biol 10:2214-2223.

Wada Y, Ohsumi Y and Anraku Y (1992) Genes for directing vacuolar morphogenesis in Saccharomyces cerevisiae. I. Isolation and characterization of two classes of vam mutants. J. Biol. Chem. 267:18665-18670.

Wang G, McCaffery JM, Wendland B, Dupre S, HaguenauerTsapis R and Huibregtse JM (2001) Localization of the Rsp5p ubiquitin-protein ligase at multiple sites within the endocytic pathway. Mol Cell Biol 21:3564-3575. 
Westphal V, Marcusson EG, Winther JR, Emr SD and van den Hazel HB (1996) Multiple pathways for vacuolar sorting of yeast proteinase A. J Biol Chem 271:11865-11870.

Wilkinson MG, Pino TS, Tournier S, Buck V, Martin H, Christiansen J et al. (1999) Sin1: an evolutionarily conserved component of the eukaryotic SAPK pathway. EMBO J 18:4210-4221.

Winzeler EA, Shoemaker DD, Astromoff A, Liang H, Anderson K, Andre B et al. (1999) Functional characterization of the $S$. cerevisiae genome by gene deletion and parallel analysis. Science 285:901-906.

Wurmser AE, Sato TK and Emr SD (2000) New component of the vacuolar class $\mathrm{C}-\mathrm{Vps}$ complex couples nucleotide exchange on the Ypt7 GTPase to SNARE dependent docking and fusion. J Cell Biol 151:551-562.

Xie Y and Varshavsky A (2000) Physical association of ubiquitin ligases and the 26S proteasome. Proc Natl Acad Sci USA 97:2497-2502.

Associate Editor: Sergio Olavo Pinto da Costa 